\title{
Screening of potential herbaceous honey plants for beekeeping development
}

\author{
Tura Bareke Kifle, Kibebew Wakjira Hora, Admassu Addi Merti
}

Holeta Bee Research Centre, Oromia Agriculture Research Institute, Holeta, Ethiopia

\section{Email address:}

trbareke@gmail.com (T. B. Kifle)

\section{To cite this article:}

Tura Bareke Kifle, Kibebew Wakjira Hora, Admassu Addi Merti. Screening of Potential Herbaceous Honey Plants for Beekeeping Development. Agriculture, Forestry and Fisheries. Vol. 3, No. 5, 2014, pp.386-391. doi: 10.11648/j.aff.20140305.19

\begin{abstract}
Availability of adequate perennial and annual sources of nectar and pollen is the most limiting factor in the survival, abundance and distribution of honeybees. The study was therefore conducted to screen the best performing bee forages from eight plant species with a view to selecting for honey production for high and mid land agro-ecologies. The planting materials were Becium grandiflorum, Vicia sativa, Guizotia abyssinica, Echium plantaginium, Trifolium rupplianum, Brassica carinata, Sinaps alba and Fagophyrum esculentum. The species were evaluated based on germination rate, number of flower heads per plants, time to set flower, foraging intensity of honeybees and flowering length. Accordingly, Becium grandiflorum, Guizotia abyssinica, Brassica carinata, Fagophyrum esculentum and Trifolium rupplianum were good under rain fed condition while Sinaps alba was found to perform better under irrigation fed. On contrary, the study found that Echium plantaginium; Vicia sativa and Fagophyrum esculentum were performed better under both rain fed and irrigation conditions. Mean number of flower heads per $1 \mathrm{~m}^{2}$ for all studied plant species were similar except Echium plantaginium which was significantly higher $(\mathrm{P}<0.05)$ compared to the rest. Honeybees foraging intensity and time for different plant species were significantly different. From these investigations, it is concluded that developing better performing plant species through use of irrigation and rain fed conditions will alleviate the shortage of bee forages and help in increasing honey production.
\end{abstract}

Keywords: Bee Forage Herbs, Flowering Period, Pollen Yield and Foraging Intensity

\section{Introduction}

Apiculture is one of the major incomes generating agricultural activity for the poorest and other beekeepers dwelling in areas where other livestock cannot exist and other income generating activity options are very limited. It also serves as means of income diversification for beekeepers in potential areas where other agriculture could be practiced including in rural and urban areas. Beekeeping contributes to country's economy through export earnings. Honey and beeswax are among the export commodities of agricultural products. Moreover, apiculture stabilizes and protects fragile environment and increase the production of agricultural food and cash crops through pollination service from honeybees. Beekeeping is one of the most important farming activities in Ethiopia (Workneh et al., 2008). According the previous studies of Ayalew (2001) and Gezahegn (2007) and Fitchl and Admasu (1994) Ethiopia has longer tradition on beekeeping than any country in the world. The contributions of beekeeping in poverty reduction, sustainable development and natural resources conservation is very high and these have been recognized and well emphasized by the government of Ethiopia. But the success of beekeeping primarily depends on the availability of prevalent bee forages which based on its population density, nectar and pollen potentiality and prolonged flowering periods (Baptist and Punchihewa, 1983). However, currently the scarcity of bee forage is becoming serious problem in central highlands due to rapid population growth, expansion of Agriculture land and encroachments into forest land. As result, the forest coverage is declining at alarming rate and herbaceous plants are largely replacing the natural forests (Admassu Addi 1996).

Herbaceous plants that grow as weed on cultivated field, neglected open lands, wastelands and grown as ornamentals are important source of bee forage (Edward, 1976) because they grow \& flourish in short period of time and their seeds can be collected easily and sown for the next growing season. However there is knowledge gap on their agronomic character, mean time taken from blooming to shedding, quantity of pollen produced and honeybee foraging intensity. 
Such information has practical applicability to select \& screen for further multiplication as bee forage source for honey production and to create awareness to protect and conserve them. Therefore, in this study attempts were made to evaluate the performance of herbaceous honey plants based on germination rate, average number of flower head per plant, foraging intensity of the honeybees, under rain and irrigation conditions to select and recommend the best bee forage source for beekeeping development..

\section{Materials and Methods}

\subsection{Description of Study Areas}

The study was carried-out at Holeta Bee research center, down apiary site, Ethiopia. The site is located at an elevation of 2400 m.a.s.l, at $09^{0} 03.5^{\mathrm{N}} \mathrm{N}$ latitude and $038^{\circ} 30.367^{ } \mathrm{E}$ longitudes. The predominant soil type in the study area are Nitisol (red soil), Mollisol and Vertisol (Wakene and Heluf, 2003; WADO, 2004).

\subsection{Seeds Collection}

For this study, mature seeds and branch cuttings / mother plants / of Becium grandiflorum, Vicia sativa, Guizotia abyssinica, Echium plantaginium, Trifolium rupplianum, Brassica carinata Sinaps alba and Fagophyrum esculentum) were collected from comparatively elite plants. The plant species were selected on the basis of: agro-ecological adaptation (growing from lowland to Afro-Montana areas), preliminary field observation and information obtained from beekeepers and literature for their importance as bee forages, similarity of their growth habit (herbaceous/herbaceous shrubs), and ease of propagation from seeds.

Seeds were collected from each plant species by selecting mature fruits. Immediately after collection, seeds were packed in perforated polyethylene bags and allowed to dry for one to one and half week at room temperature. The packages were maintained at room temperature until day of sowing.

\subsection{Experimental Management}

To evaluate the performance of the selected plant materials, seed bed were prepared by digging the ground and smoothing the field.

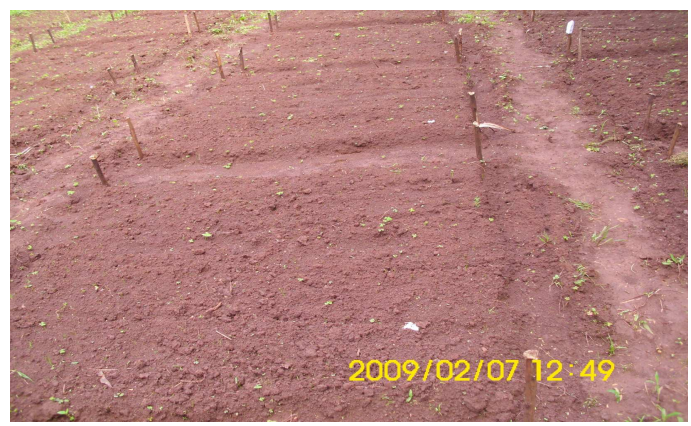

Figure 1. Land prepared for planting
Seeds were then taken out of the packages and planted on these prepared seed beds by covering with a thin layer of the same soil of the seed bed on a plot size of $2 \mathrm{mx} 2 \mathrm{~m}$ arranged in randomized block design with three replications. Dried grass stalks were used to cover the seed beds to prevent soil erosion from rain during the rainy season and for conserving moisture during the dry season. The grass covers were removed as the seeds germinated and germinant emerged to the surface of the soil. To keep proper spacing and avoid nutrient competition, spacing used between the plants and rows were 20 and $30 \mathrm{~cm}$ respectively. The necessary agronomic practices (viz., weeding etc...) were carried out except no fertilizer application to keep its natural growing state. The planting was done both at rain fed and irrigation conditions.

Then, data on days to germinate and average flower opening time was recorded. At 50\% flowering, number of flower heads was counted for each species by taking $1 \mathrm{~m}^{2}$ plot area as well as foraging intensity of honeybees on flowers was counted starting from 6: 00 a.m. to 6: 00 p.m. for ten minutes at every 2 hour interval. Also pollen yield of the flower each species was determined by collecting 50 matured flower heads having similar age and was kept for certain days to dry. For removing from the flower, pollen was shaked on paper tray and weighed using sensitive weighing balance. Moreover time from blooming to shedding and shedding were also recorded.

\section{Statistical Analysis}

The collected data were statistically analyzed by one-way ANOVA analysis of variance and descriptive statistics using Statistical Package for the Social Sciences) (SPSS) version 20.

\section{Results and Discussion}

\subsection{Germination Time}

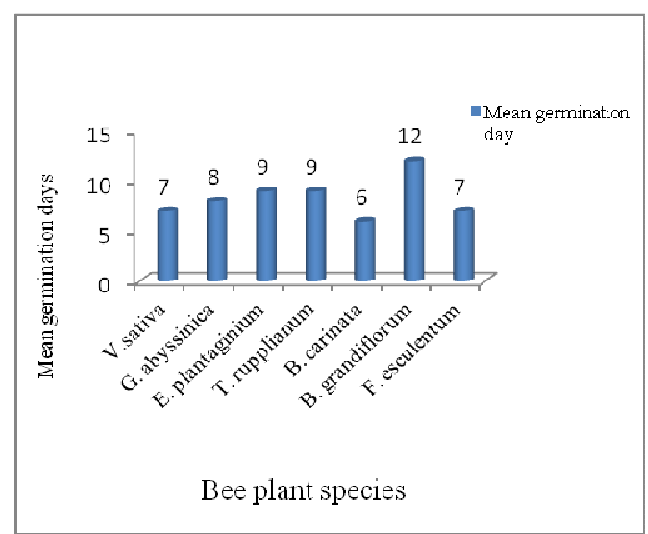

Figure 2. Mean germination days of bee forages under rain condition

Seed germination under rain fed condition began 5 days on average after incubation in Brassica carinata. In contrast, germination began after about 12 days of incubation for $B$. grandiflorum (Figure 2). Also under irrigation condition seed 
germination began after 5 days of incubation for $F$. esculentum and S. alba and this was extended to 9 days for $E$. plantaginium. See (Figure 3).This shows there is no germination problem of these bee forages plants.

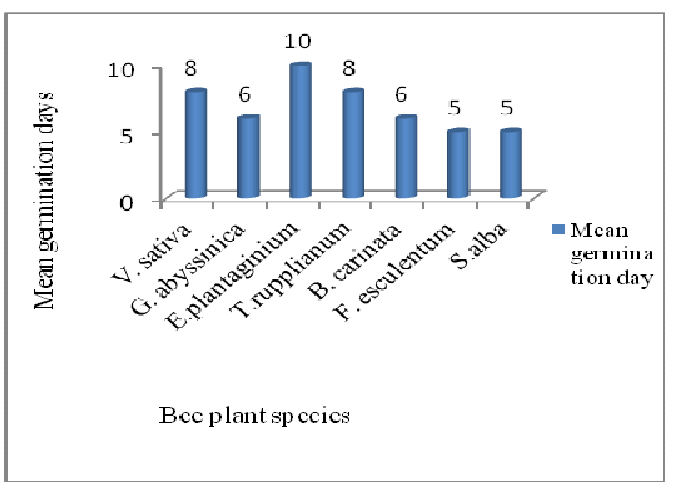

Figure 3. Mean germination days of bee forages under irrigation condition

\subsection{Time Required Set to Flower}

Mean time taken to set flower under rain fed condition for F. esculentum was 40 days, the shortest of all plants and flower shedding was occur after 31 days. On contrary, time taken to set flower was increased significantly $(\mathrm{P}<0.05)$ to 253 days and flower shedding was occur after 53 days for $B$. grandiflorum (Table 1).

Under irrigated condition, mean time taken to set flower for $F$. esculentum was again 40 days, which is similar to that of the rain fed condition, while the longest mean days 140 to set flower was recorded for E. plantaginium but the longest mean days to set flowers was recorded for $B$. grandiflorum (Table 1 and 2) The mean time required to set flower among plant species were significantly different $(\mathrm{p}<0.05)$ among each other. However, the mean time required to set flowers for $G$. abyssinica and T. rupplianum were not significantly different $(\mathrm{p}<0.05)$.

\subsection{Number of Flower Heads per $1 \mathrm{~m}^{2}$ and their Flowering Length}

Under rain condition the mean all plant species were similar except E. plantaginium which was significantly higher $(\mathrm{P}<0.05)$ compared to the rest. The number of flower heads produced by E. plantaginium per $1 \mathrm{~m}^{2}$ was 24933 compared to that of $F$. esculentum which produce only 3333 , indicating the difference of 21600 flower heads per $\mathrm{m}^{2}$. However, mean number of flower heads per $1 \mathrm{~m}^{2}$ were rather similar statistically for other studied species though it was smaller for $F$. esculentum (Table 1). Similarly, mean time taken from the start of blooming to shedding was similar for $V$. sativa, $G$. abyssinica, $T$. rupplianum, B. carinata ,B. grandiflorum and $F$. esculentum with the range of 31 to 53 days while this was significantly $(\mathrm{P}<0.05)$ higher for $E$. plantaginium with ca 95 days long blooming period (Table 1). Interestingly, availability of moisture in the soil observed to increase the duration of the blooming days though, it was not supported by quantified data.

Under irrigation condition mean number of flower heads per $1 \mathrm{~m}^{2}$ were similar for T. rupplianum, B. carinata and $G$. abyssinica. However E. plantaginium and $S$. alba were significantly different $(\mathrm{p}<0.05)$ among all plant species. The number of flower heads produced by $E$. plantaginium from $1 \mathrm{~m}^{2}$ was 13,066.7 which were also highest under irrigation condition as compared to all other plant species. $T$. rupplianum was the least which produce only 1600 , indicating the difference of $11,466.7$ flower heads per $\mathrm{m}^{2}$ when compared to E. plantaginium. Within this condition also the mean time taken from the start of blooming to shedding was similar among T. rupplianum, S. alba and F. esculentum whereas E. plantaginium, Vicia sativa and $G$. abyssinica were significantly different $(\mathrm{p}<0.05)$ among each other and all plant species. Accordingly E. plantaginium, $V$. sativa and $G$. abyssinica took long days from flower opening until shedding respectively see (Table2).

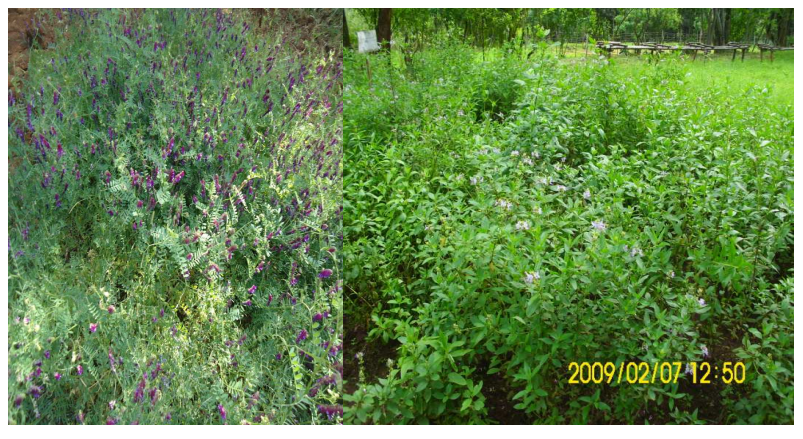

Vicia sativa

Becium grandiflorum

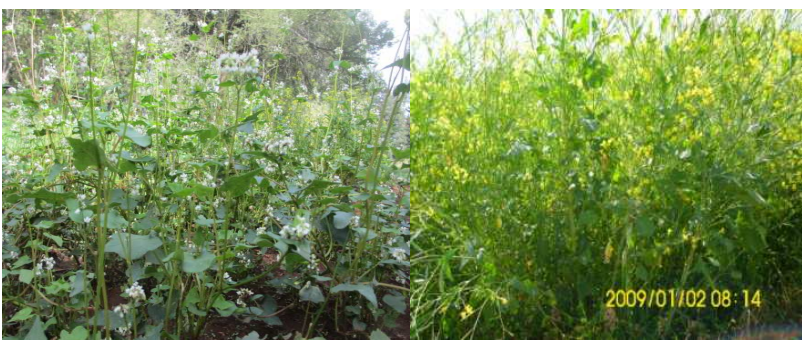

Fagophyrum esculentum Brassica carinata

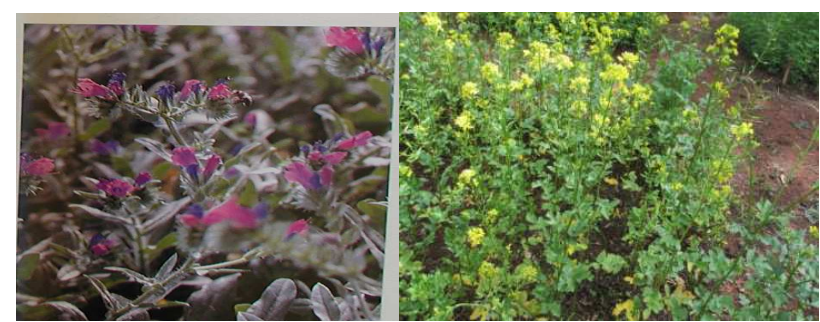

Echium plantaginium

Sinapis alba

Figure 4. Performance of planted plants

\subsection{Pollen Yield}

Pollen yield was significantly $(\mathrm{P}<0.05)$ higher for $T$. rupplianum compared to other plant species under rain condition. B. grandiflorum produce the least pollen as compared the rest. Under irrigation fed E. plantaginium was given the highest pollen yield whereas $G$. abyssinica and $B$. carinata produces the lowest. See (Table 1 and 2) 
Table 1. Mean time taken to set flower (MTSF), total number of flower head per $1 \mathrm{~m}^{2}$ (TNFHM'), pollen yield of 50 flower heads by gram (PY) and time taken from blooming to shedding (TBSH) of the following plant species using rain water fed. \pm Shows SE is standard error of the mean. Different letters in the columns shows significant differences.

\begin{tabular}{|c|c|c|c|c|}
\hline plant species & $\mathrm{MTSF} \pm \mathrm{SE}$ & TNFHM $^{2} \pm$ SE & $\mathrm{PY} \pm \mathrm{SE}$ & $\mathrm{TBSH} \pm \mathrm{SE}$ \\
\hline Vicia sativa & $90.7 \pm 0.4 \mathrm{e}$ & $11266.7 \pm 2142.7 b$ & $0.43 \pm 0 \mathrm{ab}$ & $44.8 \pm 2.8 b$ \\
\hline Guizotia abyssinica & $103.7 \pm 0.4 \mathrm{c}$ & $11333.3 \pm 735.1 b$ & $0.12 \pm 0.04 \mathrm{~cd}$ & $49.8 \pm 0.5 b$ \\
\hline Echium plantaginium & $141.5 \pm 1.2 b$ & $24933.3 \pm 5061.4 \mathrm{a}$ & $0.40 \pm 0.03 \mathrm{abc}$ & $95 \pm 10.7 \mathrm{a}$ \\
\hline Trifolium rupplianum & $96 \pm 1.2 \mathrm{~d}$ & $7600 \pm 2327.8 b$ & $0.59 \pm 0.2 \mathrm{a}$ & $33.8 \pm 0.75 b$ \\
\hline Brassica carinata & $74.8 \pm 0.4 f$ & $8266.7 \pm 2228.7 b$ & $0.09 \pm 0.0 \mathrm{~d}$ & $42 \pm 4.5 b$ \\
\hline Becium grandiflorum & $253 \pm 1 \mathrm{a}$ & $6400 \pm 1222 b$ & $0.002 \pm 0 \mathrm{~d}$ & $53 \pm 1 b$ \\
\hline
\end{tabular}

Table 2. Mean time taken to set flower (MTSF), total number of flower head per $1 \mathrm{~m}^{2}$ (TNFHM $)$, pollen yield of 50 flower heads by gram (PY) and time taken from blooming to shedding (TBSH) of the following plant species under irrigation fed

\begin{tabular}{|c|c|c|c|c|}
\hline plant species & $\mathrm{MTSF} \pm \mathrm{SE}$ & TNFHM2 \pm SE & $\mathbf{P Y} \pm \mathbf{S E}$ & TBSH$\pm \mathrm{SE}$ \\
\hline Vicia sativa & $104 \pm 0 b$ & $7333.3 \pm 352.7 b c$ & $0.15 \pm 0.00 c$ & $54.3 \pm 1.45 b$ \\
\hline Guizotia abyssinica & $98 \pm 0 c$ & $1866.7 \pm 1066.6 \mathrm{e}$ & $0.10 \pm 0.00 c$ & $41.7 \pm 1.45 c$ \\
\hline Echium plantaginium & $139.7 \pm 0.3 a$ & $13066.7 \pm 581.18 \mathrm{a}$ & $0.47+0.06 \mathrm{a}$ & $88.3 \pm 0.3 a$ \\
\hline Trifolium rupplianum & $99.3 \pm 0.7 \mathrm{c}$ & $1600 \pm 230.9 \mathrm{e}$ & $0.33 \pm 0.03 b$ & $31.7 \pm 0.88 d$ \\
\hline Brassica carinata & $72.3 \pm 0.3 d$ & $2933.3 \pm 581.18 \mathrm{de}$ & $0.1 \pm 0.01 \mathrm{c}$ & $36.7 \pm 1.3 \mathrm{~cd}$ \\
\hline Fagophyrum esculentum & $40 \pm 1.15 \mathrm{f}$ & $4666.7 \pm 352.7 \mathrm{~cd}$ & $0.19 \pm 0.0 \mathrm{c}$ & $35.3 \pm 1.3 \mathrm{~d}$ \\
\hline
\end{tabular}

\subsection{Foraging Intensity of Bees}

The number of bee visit within ten minutes per $1 \mathrm{~m}^{2}$ under rain condition, T. rupplianum was highly visited by bees followed by $V$. sativa, G. abyssinica, E. plantaginium were high as compared to $B$. carinata, $F$. esculentum and $B$. grandiflorum respectively. Whereas E. plantaginium was highly visited followed by $T$. rupplianum, $V$. sativa, $G$. abyssinica, B.carinata, F. esculentum and Sinaps alba respectively under irrigation condition. The observations recorded on the foraging rates of the pollinators which were few in the early morning and late in the evening. The foraging time of honey bees to different plant species varied and with peak foraging time ranges from 10a.m-2p.m and $12 \mathrm{a} . \mathrm{m}-4 \mathrm{p} . \mathrm{m}$ under rain and irrigation condition respectively. ( Figure5 and 6). G. abysinica, T. rupplianum, E. plantaginium and $V$. sativa were visited by bees starting early in the morning under both rain fed.

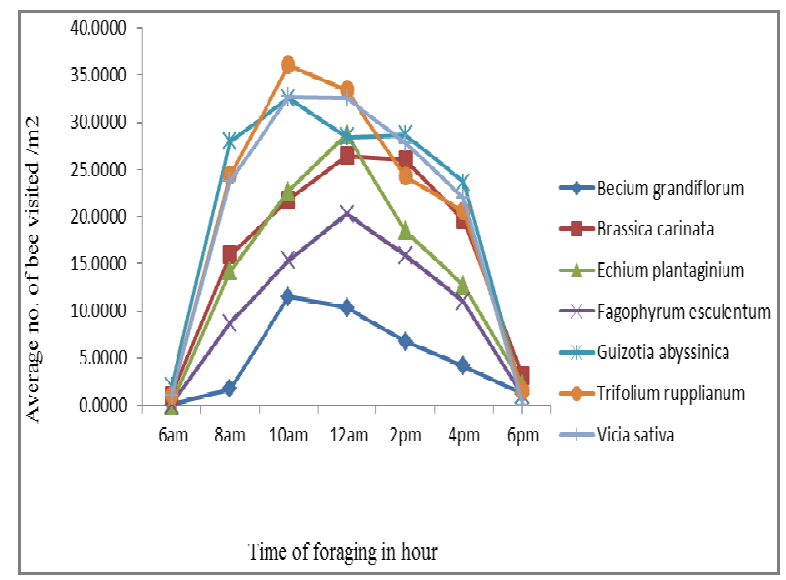

Figure 5. Foraging time (10minutes) of honeybees at different time of day on different species of plants under rain fed

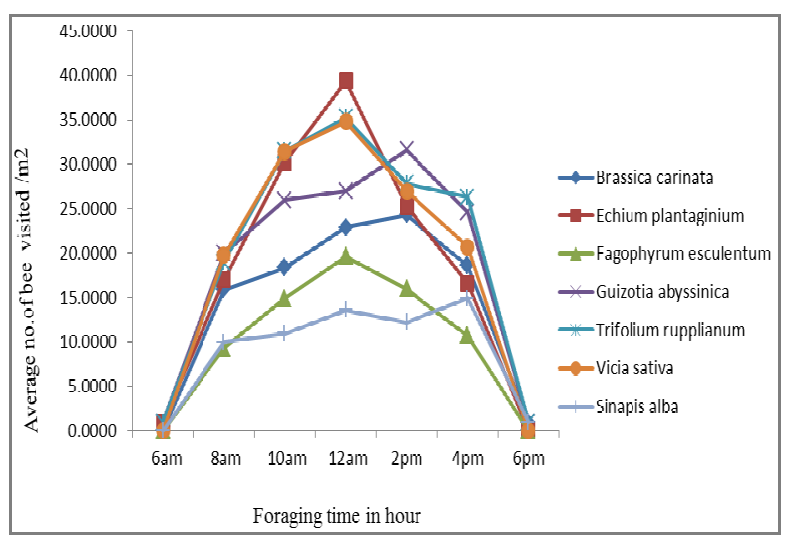

Figure 6. Foraging time of honeybees at different time of day on different species of plants under irrigation fed

\section{Discussion}

A number of flower heads per $\mathrm{m}^{2}$ of $E$. plantaginium and $\mathrm{V}$. sativa produced higher number of flower heads under both condition, due to their growing habit and crown size. More branching produces more flower heads per plant. John et al (1987) also revealed that the more vegetative growth of a plant develops to more flowers and seeds, and also plants that grow longer vegetative before flowering are typically bigger and able to support more reproductive growth. Excessive irrigation during the vegetative growth induces more flower production. From beekeeping point of view it is economical to select plant species with more flower heads and longer flowering period which provides continuous food source for the honeybee colonies.

E. plantaginium, B. grandiflorum, V. sativa and Guizotia abyssinica took long days from flower opening until shedding under both condition due to different factors such as growing temperature, photoperiod (Evans 1957).Moreover 
availability of moisture in the soil also increases the duration of flowering. Bee forage plants which take a long time from blooming to shedding are very important for honey production whereas those have short flower shedding time may be only used for bee colony buildup.

T. rupplianum, $E$. plantaginium and $V$. sativa were produced higher amount of pollen yield which are very crucial for larvae feeding. This is used to increase a number of bee colony population.

Foraging is essential to a honey bee colony's survival. To forage successfully, a bee has to learn and remember not only the color and shape of flowers that contain nectar and pollen, but also how to get to them (Menzel et al., 1996; Wehner, 2003; Collett et al., 2003). T. rupplianum, E. plantaginium, $G$ abyssinica, and $V$. sativa were foraged by bees starting early in the morning under both condition. They were also produced high amount of pollen. As a result of their pollen, they were visited starting early in the morning. Because honeybees usually collect pollen in the morning and nectar in the afternoon.Early in the morning the concentration of nectar is low due to higher humidity to attract the bees. Bees synchronize their behavior with daily floral rhythms, foraging only when nectar and pollen are at their highest levels. At other times, they remain in the hive, conserving energy that otherwise would be exhausted on nonproductive foraging flights (Moore, 2001).The variation of number of bee count is associated with different factors such as attractiveness of the flower, number of flower heads per plants nectar and pollen yield of plants and weather condition. This is also in agreement with Crane (1990) the intensity of bee visit is measure of potentiality of plants for nectar and pollen production.

\section{Conclusion and Recommendation}

In conclusion this study revealed that Becium grandiflorum, Guizotia abyssinica, , Brassica carinata and Trifolium rupplianum were good under rain fed condition while Sinaps alba and were found to perform better under irrigation fed. On contrary, the study found that Echium plantaginium; Vicia sativa and Fagophyrum esculentum were performed better under both rain fed and irrigation conditions. T. rupplianum, V. sativa, G. abyssinica, and E. plantaginium were highly visited by bees under rain fed condition respectively whereas $E$. plantaginium, $T$. rupplianum, $V$. sativa, and $G$. abyssinica were highly visited under irrigation fed. The time spent by bees for foraging on the flowers depends on the amount of nectar and pollen present in the flower. The peak foraging time is associated with nectar and pollen potentiality and floral preference of honeybees. Finally E. plantaginium, $V$. sativa and Fagophyrum esculentum were performed very well both under rain and irrigation condition, whereas G. abyssinica, T.rupplianum and Brassica carinata performed only under rain condition. From this it is concluded that developing better performing plant species through use of irrigation and rain fed conditions will alleviate the shortage of bee forages and help in increasing honey production. Even though the plants species used in this experiment showed better performance in either or under both condition, however, it requires further evaluation particularly on agronomic evaluation (seed rate and fertilizer rate) and nectar yield should be tested under different agroecologies of the country.

\section{Acknowledgements}

The author is thankful to Holeta Bee research Center and Oromia Agricultural Research Institute for providing required facilities and logistics. My sincere thanks also extended to Konjit Asfaw and Tesfaye Abera, for their inspiration and support in the implementation and follow-up of the research.

\section{References}

[1] Admasu, A. 1996 Preliminary investigation on the taxonomy of Ethiopian honey bee flora. April 18-19, 1996. Proceedings of the 4th Annual Conference of the Ethiopian Society of Animal Production (ESAP): held in Addis Ababa, Ethiopia. Pp 181-186.

[2] Ayalew, K. 2001. Bee Behaviour and Comparison of Hive Efficiency in Tigray. BoANR

[3] Baptist B.A. and R.K.W. Punchihewa, 1983. A preliminary Analysis of the principal factors will affect honey production in Sri Lanka. In: Second International Conference on apiculture in Tropical climates 1989. NewDelhi.P.95

[4] Collett, T. S., Graham, P. and Durier, V. (2003). Route learning by insects. Curr. Opin. Neurobiol. 13, 718-725.

[5] Crane, E., 1990.Bees and beekeeping, science, practice and world resource Heinemann Newness, London

[6] Edwards, S., 1976. Some wild flowering plants of Ethiopia. Addis Ababa University press. Addis Ababa, Ethiopia

[7] Evans, L.T.1957. The broad bean in experimental control of plant growth. PP 124 - 128.

[8] Fichtl, R. and Admasu, A. 1994. Honey bee flora of Ethiopia .The National Herbarium, Addis Ababa University and Deutscher Entwicklungsdieenst (DED). Mergaf Verlag, Germany.

[9] Gezahegn, T. (2007). Adaptation trial of honey plants: adaptability trials of temperate honey plants in Ethiopia. Ethiopian Beekeepers Association newsletter Vol.5, NO.1, pp 16-17.

[10] John B A, Gordon R H and Parrish D J 1987 Plant Science. McGraw-Hill publishing Company.126582.

[11] Menzel, R., Geiger, K., Chittka, L., Joerges, J., Kunze, J. and Muller, U. (1996). The knowledge base of bee navigation. $J$. Exp. Biol. 199, 141-146.

[12] Moore, D. (2001). Honey bee circadian clocks: behavioral control from individual workers to whole-colony rhythms. $J$. Insect Physiol. 47, 843-857.

[13] WADO.2004.Walmara district agricultural district office 9Archive). 
[14] Wakene Negasa and Heluf Gebrekidan .2003.Form of phosphorus and status of available micronutrients under different land use systems of Alfisolsin Bako area of Ethiopia : Ethiopian Journal of Natural Resources .5(1):21.

[15] Wehner, R. (2003). Desert ant navigation: how miniature brains solve complex tasks. J. Comp. Physiol. A 189, 579-588.
[16] Workneh, A., pusker and Karippai, R. 2008. Adapting improved box hive in Atsbi wemberta District of Eastern Zone, Tigray Region: determinants and financial benefits. IPMs (Improving Productivity and Market Access) of Ethiopian Farmers Project Working Paper 10 ILRI (International Livestock Research Institution). Nairobi, Kenya. pp30. 